\title{
Experiences with Inter-year Capstone Design Teams
}

\author{
D.D. Mann \\ Department of Biosystems Engineering, \\ University of Manitoba, \\ Winnipeg, MB R3T 5V6 \\ (Danny_Mann@umanitoba.ca) \\ K.J. Dick \\ Department of Biosystems Engineering, \\ University of Manitoba, \\ Winnipeg, MB R3T 5V6 \\ (kjdick@ms.umanitoba.ca)
}

\author{
D.S. Petkau \\ Department of Biosystems Engineering, \\ University of Manitoba, \\ Winnipeg, MB R3T 5 V6 \\ (petkau@cc.umanitoba.ca)
}

\author{
S. Ingram \\ Design Engineering, \\ University of Manitoba, \\ Winnipeg, MB R3T 5V6 \\ (sandra_ingram@umanitoba.ca)
}

\begin{abstract}
Design teams in industry are composed of individuals with diverse backgrounds at various stages of their careers. A unique set of group dynamics will be created with one member, likely someone with sufficient experience, assuming the responsibility of being the team leader. Design teams formed in engineering classes within the university setting typically consist of individuals at the same stage of their academic training, thus students do not experience the same group dynamics as they will find in industry. In an attempt to give undergraduate engineering students this experience, inter-year design teams were formed from engineering students registered in courses representing different stages of completion of the engineering degree. Students registered in the final-year design course were expected to assume the roles of team leaders or coleaders. This paper will discuss a number of issues that were observed with inter-year capstone design teams. It has been concluded that the disadvantages of inter-year design teams outweigh the advantages.
\end{abstract}

\section{Introduction}

The capstone design experience in the Department of Biosystems Engineering, University of Manitoba consists of three, 13-week courses that students take throughout their engineering program. Typically, students will complete one of these courses in each of the final three years of their program. This sequence of mandatory design courses has come to be known as the "Design Trilogy." Details of the Design Trilogy can be reviewed from the following publications $[4,5]$.

Prior to the fall of 2006, the three Design Trilogy courses were taught independently. Thus, design teams were formed independently by each of the course instructors. Students registered in Design Trilogy I were expected to generate a purely conceptual solution to a design problem. Design Trilogy II students were expected to go beyond the conceptual stage; appropriate engineering analysis of the design was to be completed. Design Trilogy III students were expected to provide detailed designs. Expectations for the design projects increased as the students gained academic training. It is important to note that the design teams (for all three of the courses) were composed of students having similar levels of academic training. Team leaders were identified by each design team. In many cases, there was no formal selection or appointment of a team leader; an individual simply assumed the role as deadlines approached.

In industry, design teams are often composed of individuals with diverse backgrounds at various stages of their careers. An individual with sufficient experience will be assigned to function as the team leader. In an attempt to give undergraduate engineering students an experience similar to what they will find in industry, inter-year design teams (termed "vertical integration" in the literature) were formed in 2006 from engineering students registered in all three of the Design Trilogy courses. Each design team consisted of one or two students from each of the 
three Design Trilogy courses. Students registered in Design Trilogy III were expected to assume the roles of team leaders or co-leaders for each of the projects.

Such an idea is not without merit. The notion of interyear design teams receives support from the engineering education literature. There is evidence to suggest that integrating students with multiple skill and academic levels on a common design project enhances students' learning process in that it fosters productivity and complex problem-solving [1,2]. In their assessment of an integrated design project in a chemical engineering course involving first year and fourth year students, Giralt et al. [3] argue that the learning experience benefits both junior and senior students alike. The role of fourth year students as project managers and team leaders improved their understanding of the management experience. Similarly, the first-year students, along with gaining an appreciation for team-based learning, found working with fourth year students increased their learning abilities and confidence.

Thus, the change that was implemented in the Design Trilogy in September 2006 was expected to be a positive change. This paper discusses several unanticipated outcomes.

\section{Student Reaction and Instructor Observation}

Prior to the conclusion of the semester (fall of 2006), the Design Trilogy instructors made a point of talking to the undergraduate students to get informal feedback regarding inter-year design teams. Students understood that the intent was for the senior students to provide leadership and mentoring to the junior students in each group. Four key issues were identified as disadvantages of using inter-year design teams in the university setting.

The first issue, a logistical issue, relates to the difficulty associated with scheduling team meetings outside of class time. Any "spares" that exist within a weekly schedule tend to fall at different times for students taking second, third, or fourth-year classes. For team meetings to happen during "working hours", one or more students would be forced to choose between skipping class (from a different course) or missing the team meeting. The only other alternative was to schedule team meetings on weekends or during the evenings. Meetings scheduled at these times tended to interfere with part-time jobs. It should be noted that this issue could be overcome (at least partially) by devoting more of the scheduled lecture and/or laboratory time to team meetings.

The second issue relates to team leadership. The structure imposed on the engineering students did not always empower those with the best leadership skill. In some cases, Design Trilogy I or II students felt they had to suppress their natural leadership abilities because they had to defer to the more senior member of their team. Some of the Design Trilogy III students were uncomfortable with the responsibility of functioning as a team leader. For several of the design teams, the leadership received was less than it should have been based on the leadership skills represented on the team. It had been assumed that students registered in Design Trilogy III, having completed the most courses towards their engineering degree, would be best prepared for the role of leading a team. This informal feedback suggests that stage of completion of one's engineering degree is not a good indicator of one's ability to function as an effective team leader. Although some of the students who were forced to become team leaders were reluctant to assume these responsibilities, the experience was likely a great learning experience. These individuals will be better prepared for these responsibilities the next time they are asked to assume the role.

A third issue can likely be attributed to the inexperience of the team leaders. In some situations, the team leaders assumed all of the project roles. The junior students felt intimidated and stepped aside to allow the leaders to overrun the process. A good example of this dynamic became evident upon review of the student design journals at the end of the semester. It is evident that the Design Trilogy III students assumed complete responsibility for the writing and formatting of the written report. Perhaps they did not have confidence in the junior members of their teams. Rather than trying to mentor their junior colleagues, they simply took the work away from the junior colleagues.

A fourth issue relates to the loss of "informal" design time. Students in Design Trilogy II and III commented that, in previous years, much informal discussion of their design projects occurred during the breaks between classes when they were physically walking from room to room or from building to building. These 10-min discussions served the function of keeping the student's minds thinking about their design projects throughout the day. During the fall 2006 semester, much of this informal design time was inadvertently omitted because of the inter-year composition of the design teams. In other words, the 
design team was not together during these 10-min breaks between classes.

Overall, student reaction to the inter-year design teams was negative. Many students assured the instructors that they understood the intent behind inter-year design teams. However, the general consensus was that this theory was flawed. Although an educational institution should not simply bow to the wishes of its students, there is wisdom in hearing what the students have to say. In this particular case, we (as instructors) also had the sense that the inter-year design teams were not functioning as well as had been anticipated. Each instructor was responsible for one of the Design Trilogy courses; at the same time each instructor had been designated as the advisor to three or four design teams. There seemed to be a disconnect between the design teams and the academic advisors because the composition of the students in the design teams being advised was different than the composition of the students attending the lectures. Consequently, the instructors were not able to establish a good rapport with all of the members of the design teams.

Although much attention had been paid to details when scheduling the three courses, the three courses did not flow as smoothly as desired. To be frank, it seemed like chaos at times. Design team meetings were happening at the same time as laboratory activities; instructors were trying to be available to advise their design teams while also supervising laboratory activities. There was miscommunication (or at least misinterpretation) of assignments and due dates because students were hearing explanations from a couple of different instructors.

From the perspective of the instructors, the semester began with great optimism. There was confidence and excitement that the students were going to experience a great learning environment because of the inter-year design teams. Early in the semester, optimism prevailed as the team dynamics during team meetings was observed; the teams seemed to be functioning well. By mid semester, however, problems (or at least complaints) began to surface. By the end of the semester, instructor reaction to the inter-year design teams was also negative.

\section{Conclusions}

Design teams in industry are composed of individuals with diverse backgrounds at various stages of their careers. The typical capstone design class in a university setting does not accurately reflect the range of engineering experience because all students are typically at the same stage of completion of their degrees. The creation of inter-year design teams was hypothesized to better reflect the expected range of engineering experience within a design team. Four issues were observed during trial inter-year design teams. Scheduling team meetings outside of class time was extremely difficult due to the different academic schedules of the students in different years of their programs. Team leadership suffered because some of the senior students were uncomfortable providing leadership; "natural" leaders within the team were forced to suppress their natural leadership abilities because they had to defer to the more senior member of their team. Furthermore, the team leaders did not fully trust their junior teammates; rather than mentoring the junior members of the team, the leaders simply assumed responsibility of the various tasks. Perhaps the greatest oversight was the loss of the informal design time that previously had taken place during the 10-min breaks between classes as the entire design team traveled together throughout the day. It has been concluded that the disadvantages of interyear design teams outweigh the advantages.

\section{References}

[1] Auchey, F., T. Mills and G. Auchey. 1998. Reengineering the undergraduate building contruction program for the $21^{\text {st }}$ century. Journal of Engineering Education 87(1):71-78.

[2] Coyle, E., L. Jamieson, and W. Oakes. 2005. EPICS: engineering projects in community service. International Journal of Engineering Education 21(1):139-150.

[3] Giralt, F., J. Herrero, F. Grau, J. Alabart and M. Medir. 2000. Two way integration of engineering education through a design project," Journal of Engineering Education 89(2):219-229.

[4] Mann, D.D., K.J. Dick, D.S. Petkau, M.G. Britton and S. Ingram. 2005. Using mastery learning to teach the engineering design process. In Proceedings of the $2^{\text {nd }} C D E N$ Design Conference. Kananaskis, AB, July 17-20.

[5] Mann, D.D., S. Ingram, K.J. Dick, D.S. Petkau and M.B. Britton. 2007. Concurrent teaching of technical communication and the engineering design process. ASABE Paper No. 078003. St. Joseph, MI: ASABE. 